\title{
Let the sun shine in: effects of ultraviolet radiation on invasive pneumococcal disease risk in Philadelphia, Pennsylvania
}

\author{
Alexander NJ White ${ }^{1,2}$, Victoria Ng1,5, C Victor Spain ${ }^{4}$, Caroline C Johnson ${ }^{4}$, \\ Laura M Kinlin ${ }^{1,3}$ and David N Fisman*1,2,3
}

\begin{abstract}
Address: ${ }^{1}$ Child Health Evaluative Sciences, Research Institute of the Hospital for Sick Children, 123 Edward Street, Toronto M4V 1X6, Canada, ${ }^{2}$ Faculty of Medicine, University of Toronto, 1 King's College Circle, Toronto M5S 1A8, Canada, ${ }^{3}$ Dalla Lana School of Public Health, University of Toronto, Toronto M4T 3M7, Canada, ${ }^{4}$ Division of Disease Control, Philadelphia Department of Public Health, 500 South Broad Street, Philadelphia 19146, USA and ${ }^{5}$ National Centre for Epidemiology and Population Health, The Australian National University, Canberra 0200, Australia

Email: Alexander NJ White - anjwhite@gmail.com; Victoria Ng - msvictoriang@gmail.com; C Victor Spain - charles_spain@merck.com; Caroline C Johnson - carolinecjohnson@verizon.net; Laura M Kinlin - laura.kinlin@dal.ca; David N Fisman* - david.fisman@gmail.com

* Corresponding author

Published: 4 December 2009

BMC Infectious Diseases 2009, 9:196 doi:10.1186/147|-2334-9-196

Received: 13 October 2008

Accepted: 4 December 2009

This article is available from: http://www.biomedcentral.com/I47I-2334/9//96

(C) 2009 White et al; licensee BioMed Central Ltd.

This is an Open Access article distributed under the terms of the Creative Commons Attribution License (http://creativecommons.org/licenses/by/2.0), which permits unrestricted use, distribution, and reproduction in any medium, provided the original work is properly cited.
\end{abstract}

\begin{abstract}
Background: Streptococcus pneumoniae is a common cause of community acquired pneumonia and bacteremia. Excess wintertime mortality related to pneumonia has been noted for over a century, but the seasonality of invasive pneumococcal disease (IPD) has been described relatively recently and is poorly understood. Improved understanding of environmental influence on disease seasonality has taken on new urgency due to global climate change.
\end{abstract}

Methods: We evaluated 602 cases of IPD reported in Philadelphia County, Pennsylvania, from 2002 to 2007. Poisson regression models incorporating seasonal smoothers were used to identify associations between weekly weather patterns and case counts. Associations between acute (dayto-day) environmental fluctuations and IPD occurrence were evaluated using a case-crossover approach. Effect modification across age and sex strata was explored, and meta-regression models were created using stratum-specific estimates for effect.

Results: IPD incidence was greatest in the wintertime, and spectral decomposition revealed a peak at 51.0 weeks, consistent with annual periodicity. After adjustment for seasonality, yearly increases in reporting, and temperature, weekly incidence was found to be associated with clear-sky UV index (IRR per unit increase in index: 0.70 [95\% Cl 0.54-0.9I]). The effect of UV index was highest among young strata and decreased with age. At shorter time scales, only an association with increases in ambient sulphur oxides was linked to disease risk (OR for highest tertile of exposure $0.75,95 \% \mathrm{Cl} 0.60$ to 0.93$)$.

Conclusion: We confirmed the wintertime predominance of IPD in a major urban center. The major predictor of IPD in Philadelphia is extended periods of low UV radiation, which may explain observed wintertime seasonality. The mechanism of action of diminished light exposure on disease occurrence may be due to direct effects on pathogen survival or host immune function via altered I,25- $(\mathrm{OH})_{2}$-vitamin-D metabolism. These findings may suggest less diminution in future IPD risk with climate change than would be expected if wintertime seasonality was driven by temperature. 


\section{Background}

Many infectious diseases of public health importance exhibit predictable periodicity, with major increases in incidence during a specific season of the year [1]. Empirical evidence of such "seasonality" has been noted by physicians for centuries, and has been prominent enough to become a part of our vernacular (e.g., "cold and flu season") $[1,2]$. Despite this wealth of experiential evidence, the mechanisms underlying seasonality are poorly understood, especially diseases characterized by person-to-person transmission [1].

Invasive bacterial disease due to Streptococcus pneumoniae and other respiratory pathogens exhibits striking seasonality in its occurrence [3-7]. Pneumococcal infections are a common cause of severe, community-acquired illnesses, including community-acquired pneumonia requiring hospitalization, bacteremia, and meningitis [8]. While the introduction of antibiotics dramatically reduced the case fatality rate (CFR) for pneumococcal disease, the current CFR for bacteremic pneumococcal disease is still estimated at $5-10 \%$ in the United States, and may be twice as high among the elderly and in cases of meningitis $[9,10]$. The emergence of antimicrobial resistance to beta-lactam agents, macrolides, and other antibiotic classes is an important clinical concern [11]. Although the introduction of conjugate pneumococcal vaccines has been associated with a reduction in disease incidence [12], the recent increase in invasive infection by non-vaccine serotypes [13], which may be highly resistant to commonly-used antimicrobials [14], suggests that this microorganism will persist in challenging both the medical and public health communities.

The incidence of IPD peaks in the winter months, with annual periodicity $[4,5]$, but the forces that drive this characteristic seasonality are unknown. Wintertime seasonality of communicable respiratory diseases are often assumed to be driven by seasonal changes in environmental conditions (e.g., diminished ultraviolet radiation (UV) exposure, decreased temperature) but such associations may be confounded by other seasonally varying factors, including population behaviours (e.g., clustering indoors), co-occurrence of other infections (e.g., influenza) [4], and frequency of laboratory testing [15].

A more thorough understanding of the effect of environmental factors on seasonal IPD incidence could offer significant insight into pathogenesis, improve disease forecasting, and help determine the likely direction of pneumococcal disease incidence in the face of global climate change [16]. Our objective was to investigate how environmental factors influence IPD occurrence in Philadelphia County. We used both traditional analytic methods (i.e., Poisson regression with seasonal smoothers) and a novel case-crossover method to examine the effects of acute weather fluctuations on IPD occurrence. Both methods reduce confounding by environmental, behavioural, and infectious influences that might otherwise distort the observed magnitude of environmental effects on disease risk.

\section{Methods}

Philadelphia County encompasses an area of $369 \mathrm{~km}^{2}$ in south-eastern Pennsylvania, and is coterminous with the City of Philadelphia (population 1,517,550 in the year 2000 [17]). The population receives public-health services from the Philadelphia Department of Public Health (PDPH). IPD has been a notifiable condition in the Commonwealth of Pennsylvania since 2002; Pennsylvania uses the uniform case definition endorsed by the National Notifiable Diseases Surveillance System [18]. A case is considered "confirmed" when a consistent clinical syndrome occurs in association with the isolation of S. pneumoniae from a normally sterile site (e.g. blood, cerebrospinal or pleural fluid). Data on IPD case occurrence in Philadelphia was obtained from PDPH records, and included date of onset, age, sex, race and ethnicity of the patient, isolation site, and fatal outcome (if known).

\section{Environmental Exposure Data}

Meteorological data including temperature, relative humidity, wind speed, atmospheric pressure, and precipitation for the period from 2002 to 2006 was obtained from the weather station at Philadelphia International Airport, located eight kilometres southwest of Philadelphia's city center [19]. Information pertaining to air quality in Philadelphia County during the years of interestincluding concentrations of lead, ozone, sulphur oxides and particulate matter-was obtained from the Environmental Protection Agency [20]. Because daily readings were taken at various locations throughout the region, the arithmetic means of the air quality values were used as exposure variables. UV index forecast estimates for Philadelphia during the same period were retrieved from the National Weather Service Climate Prediction Center [21]. Clear-sky UV indices represent an integral of measured UV radiation levels weighted by the ability of the different UV wavelengths to cause skin erythema. The issued UV index is a similar measure, which accounts for the effect of clouds on radiation transmission; because of inconsistencies in cloud measurement during the study period, we used the clear-sky UV index as our exposure variable.

\section{Statistical Methods}

Rates of invasive pneumococcal disease were calculated using demographic data for Philadelphia County from the year 2000 US Census, as well as 2006 population estimates from the Bureau of the Census, with linear interpolation and extrapolation used to generate estimates for 
population by age and sex in other years [17]. We evaluated the seasonality of disease occurrence through construction of periodograms and autocorrelograms $[15,22]$ for weekly case counts. As yearly periodicity was observed, we estimated seasonal and year-on-year trends in IPD occurrence using Poisson regression models that incorporated sine and cosine oscillators, with 52 week (annual) frequencies (i.e., incorporated fast Fourier transforms) $[7,22]$.

Using these parameters, the expression for the expected number of case counts for a given week, $E(Y)$ is given by:

$E(Y)=\exp \left(\alpha+\beta_{1}(\right.$ cases $)+\beta_{2}(\sin (2 \cdot \pi \cdot$ week $/ 52))+\beta_{3}(\cos (2 \cdot \pi \cdot$ week $/ 52))+\beta_{4}($ year $)+\beta_{5}\left(\right.$ year $\left.\left.^{2}\right)+\right)$ where cases is an autoregressive model term reflecting the cumulative case count in the month prior to case occurrence, (i.e., cases $=\sum_{i=t-1}^{t-4} Y_{i}$ ).

The phase-shift of the composite waveform generated by combining sine and cosine components of the above equation can be approximated as the arctangent of $\beta_{2} / \beta_{3}$, and can be used to estimate the timing of peak disease incidence [22]. We also included model terms that controlled for longer term trends in incidence of invasive pneumococcal disease, which may have reflected the initiation of surveillance, the introduction of public funding for conjugate pneumococcal vaccination [12], changes in medical diagnostic practices, or other long-term changes in real or apparent pneumococcal epidemiology. As yearon-year trends in disease occurrence reflected a non-linear increase in disease risk, we used models that incorporated both linear and quadratic yearly terms.

The quadratic model term was statistically significant, but is difficult to interpret, thus we present our final Poisson model with separate linear yearly terms for the period from 2002 to 2003, and the period from 2004 to 2007 [23]. We evaluated the impact of environmental exposures on weekly IPD incidence by incorporating exposure variables into Poisson models both individually, and using a backwards elimination algorithm (with variables retained for $P<0.2[24]$ ).

To explore the possibility of effect modification by subject characteristics, we evaluated stratum-specific estimates of effect for age categories and genders. Heterogeneity of effects across strata was assessed using meta-analytic techniques, including both graphical inspection and calculation of meta-analytic Q-statistics [25]. We further explored the sources of between-stratum heterogeneity through construction of meta-regression models that estimate the contribution of group-level covariates to between-stratum variation in effects [25].
We used a case-crossover approach to evaluate acute (i.e., daily) associations between environmental exposures and IPD occurrence. This approach provides a means for evaluating the association between brief, transient exposures and rare outcomes. The design is characterized by "self matching", in that cases serve as their own controls. In the context of environmental epidemiology, a "case" is a day on which a case occurred, while a "control" is an appropriately selected day on which a case did not occur [6]. We used a time-stratified 2:1 matched case-crossover design in which hazard periods were defined as the reported date of IPD onset from Philadelphia County public health. Beginning on January 1, 2002 the person-time at risk was divided into three-week time strata. Control periods were chosen by matching the hazard period by day of the week within the stratum, and could both precede, both follow, or straddle the hazard period $[26,27]$. Random directionality of control selection was used in order to avoid biases that can occur with unidirectional or uniform bidirectional control selection [26]. The 1-3 day incubation period of $S$. pneumoniae was used to estimate the lag days between acute environmental occurrence and case onset, or plausible effect period [28]. We also evaluated effects during the period immediately preceding incubation (i.e., 4-6 day lags) to evaluate the possibility that environmental conditions might affect risk via enhanced transmission of $S$. pneumoniae. We evaluated the effects of both raw environmental exposures, and quantile ranks within time strata through construction of conditional logistic regression models [24]. Analyses were performed using SAS version 8.01 (SAS Institute, Cary, NC) and Stata version 9.1 (Stata Corporation, College Station, TX).

\section{Results \\ Descriptive Epidemiology}

Between January 1, 2002 and April 30, 2007 there were 602 reported cases of IPD in Philadelphia County, for a crude annual incidence of 6.84 cases per 100,000 [95\% CI 6.32 to 7.42 ]. Incidence of IPD was highest at the age extremes, with a slight male:female predominance (incidence rate ratio (IRR) $1.16,95 \% \mathrm{CI} 0.99$ to 1.36 ); the case fatality rate was approximately $10 \%$ (Table 1 ).

Both spectral decomposition and construction of autocorrelograms identified annual periodicity of infection, with peak incidence in mid-February (phase $=6$ weeks) (Figures 1 and 2). Strong statistical evidence for seasonal oscillation was obtained from Poisson regression models $(P$ for seasonal oscillation $<0.001)$. A significant annual increase in incidence was seen throughout the study period, though this was more marked prior to 2004 (IRR per year $1.34,95 \%$ CI 1.08 to 1.66 ) than subsequently (IRR 1.22, per year 95\% 1.16 to 1.34 ) (Figure 3). We found no clear trends in the incidence of IPD or case-fatality in individual age groups, and no significant heteroge- 
Table I: Epidemiology of Invasive Pneumococcal Disease in Philadelphia County, 2002-2007.

\begin{tabular}{lcc}
\hline \multicolumn{1}{c}{ Age } & Cases & Incidence per 100,000 Person-Years of Observation \\
\hline 0 to 4 & 55 & 9.67 \\
5 to 14 & 12 & 0.92 \\
15 to 24 & 13 & 0.98 \\
25 to 39 & 74 & 3.80 \\
40 to 59 & 254 & 12.21 \\
60 to 79 & 136 & 11.08 \\
80 and over & 58 & 16.74 \\
\hline Gender & & \\
\hline Male & 302 & 7.39 \\
Female & 300 & 6.37 \\
\hline Died & $53(9.46 \%)$ & - \\
\hline Total & 602 & 6.84 \\
\hline
\end{tabular}

neity was detected between age groups with respect to year-on-year trends in incidence or case-fatality (see Additional File 1 and Additional File 2).

\section{Weekly Environmental Effects}

In univariable models the risk of IPD increased with several seasonally oscillating environmental exposures, including temperature, humidity, pressure, air pollution, and UV radiation, as shown in Table 2. Risk of IPD increased with average weekly barometric pressure, sulphur and nitrous oxides, and decreased with average weekly temperature, relative humidity, and UV index. However, after controlling for seasonal oscillation and longer term temporal trends, only cooling-degree days (i.e., average number of degrees above $18^{\circ} \mathrm{C}$ ), maximum temperature, and clear-sky UV index were independently associated with case occurrencein a final multivariable model (Table 2). Risk increased with increasing maximal temperature, but decreased with cooling degree days, indicating a threshold of $18^{\circ} \mathrm{C}$ above which the qualitative effect of temperature changed.

There was significant heterogeneity in the effect of clearsky UV index in individuals aged less than 15 years (IRR $0.26,95 \%$ CI 0.11 to 0.61 ) as compared to older individuals (IRR $0.81,95 \%$ CI 0.64 to 1.03 ), (Q-statistic 6.31 on 1 d.f., $P=0.012$ ). No heterogeneity in UV effects was found when evaluated in individuals aged over 64 as compared to younger individuals (Q-statistic 0.48 on 1 d.f., $P$ $=0.523)$, or when evaluated in males as compared to females (Q-statistic 1.68 on $1 d . f ., P$ for heterogeneity = $0.194)$. Meta-regression models constructed using stratum-specific estimates of effect for age groups, by 10-year age increments, identified a log-linear trend in the effect of $U V$ radiation on disease risk by age stratum, with strongest effects in youngest strata, and effects diminishing with increasing age (change in natural logarithm of IRR $=0.13$ per decade, $95 \%$ CI 0.04 to $0.23, P=0.007$ ) (Figure 4).

\section{Acute Environmental Effects}

Evaluating associations between environmental and meteorological exposures and IPD risk using a case-crossover approach, we identified an inverse association between ambient levels of sulphur oxides and disease risk during the likely incubation period (Table 3 ). No other significant associations between environmental exposures and risk were identified either during the incubation period, or in the period immediately prior to incubation. In particular, occurrence of IPD was not affected by daily changes in clear-sky UV index, temperature or coolingdegree days, in contrast to associations on longer time scales described above.

\section{Discussion}

Notwithstanding the existence of vaccination and effective antibiotic therapy, invasive pneumococcal disease remains an important source of population morbidity and mortality. The seasonality of IPD is well recognized, but poorly understood. Epidemiological mechanisms invoked to explain this pattern have included co-occurrence of other infectious diseases [4], wintertime social gatherings [5], and seasonal oscillation in immune function [29]. However, concurrent seasonal changes in a variety of environmental, behavioural, and epidemiogical exposures make identification of causal associations particularly challenging [30]. We attempted to address this challenge by using analytic approaches that should control for seasonal confounders, known and unknown, at different time scales. At a weekly time scale we found 


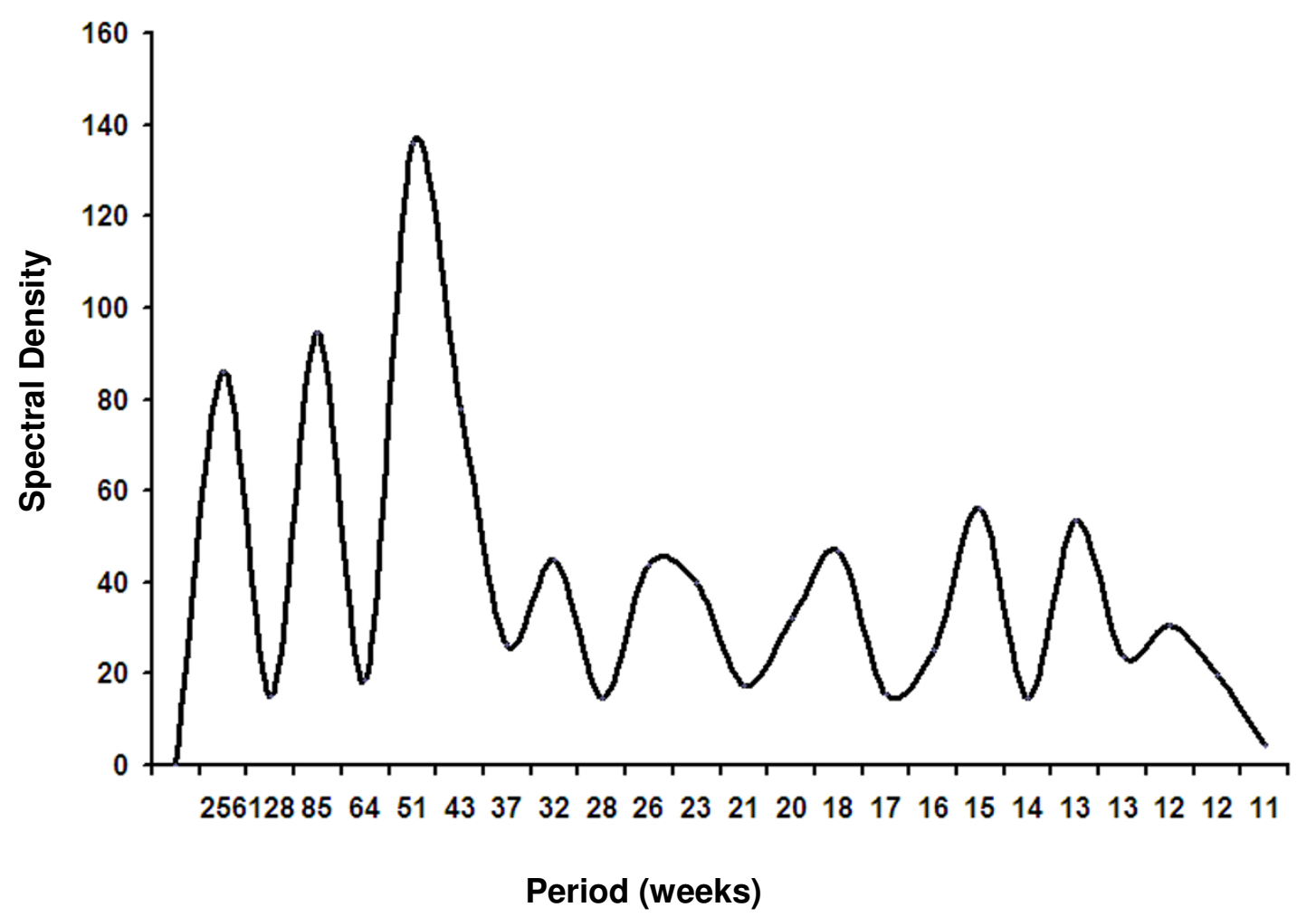

Figure I

Periodogram Constructed from Spectral Decomposition of Weekly Pneumococcal Case Counts. Spectral density is represented on the $y$-axis, and can be conceptualized as a measure of goodness-of-fit for oscillatory regression models at different frequencies. The large peak at a frequency of $5 \mathrm{I}$ weeks suggests that invasive pneumococcal disease is a process that oscillates with annual periodicity (and is, in other words, compatible with wintertime seasonality). The two peaks at lower frequencies are lower harmonics illustrating bi- and tri-annual behaviour.

increases in UV radiation to be most strongly associated with decreased numbers of invasive pneumococcal disease cases, though average temperatures also appeared to influence disease risk. At short time scales, fluctuations in ambient air quality, as manifested by differences in concentrations of sulphur oxides, were associated with changes in risk. The direction of this association was at variance with existing models relating air pollution to pneumonia occurrence $[3,31,32]$.

The casual (as opposed to causal) association between low UV radiation in the winter and surges in respiratory disease has been noted previously [33], and has been proposed as an important driver of influenza seasonality, but has not to our knowledge been evaluated in a way that accounts for coincident seasonal changes in other seasonally oscillatory factors. The degree to which such seasonal oscillation can result in "just so" stories that lead to misattribution of causation to non-specific seasonal exposures is highlighted in the univariable analyses we conducted without including seasonal oscillators. In these models, a variety of environmental conditions, including weather variables and air quality indices, were strongly associated with IPD risk. However, after controlling for non-specific seasonality, only UV radiation (and, more weakly, temperature) were associated with disease risk; indeed, the apparent protective effect of UV radiation was actually strengthened after controlling for seasonal oscillation. The interpretation of such a model is that increases in UV radiation reduce IPD risk, even after accounting for the fact that IPD risk is maximal during low-UV periods of the year.

An important consideration is whether changes in UV radiation, operating at a weekly time scale, constitute a biologically plausible mechanism that explains seasonal oscillation in pneumococcal disease risk. Indeed, there are several mechanisms that may have substantial biological plausibility. Modulation of risk may occur through direct effects of UV radiation on host immune function: Dowell 


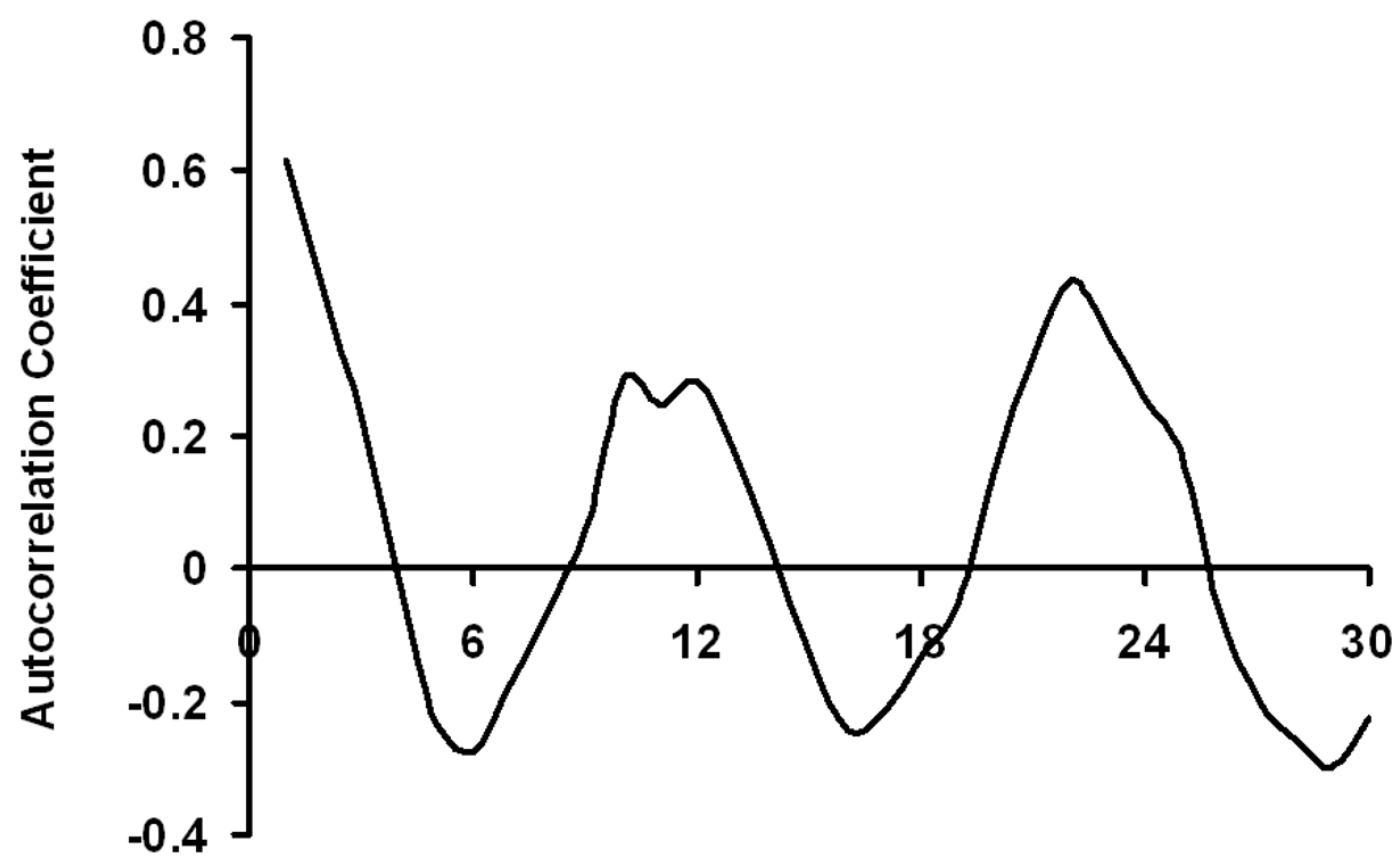

\section{Lag (Months)}

Figure 2

Autocorrelogram for Weekly Invasive Pneumococcal Case Counts in Philadelphia, 2002 to 2007. Positive autocorrelation is observed at intervals of 12 months, and negative autocorrelation is observed at intervals of 6 months, consistent with steady seasonal oscillation in disease risk.

reviewed a variety of immunological changes associated with diminished UV radiation exposure in experimental settings, and noted that in granulocyte and monocyte function were reduced during periods of short light exposure [33]. UV radiation also influences the production of 1,25-(OH $)_{2}$-vitamin $\mathrm{D}$, which has important immunomodulatory functions [34]. Namely, enhanced maturation of macrophages, macrophage secretion of bactericidal substances such as lysozomal enzyme phosphatase and hydrogen peroxide [33,35], and secretion of antimicrobial peptides (including cathelicidins and defensins) by both immune cells, and respiratory tract epithelium [36]. Vitamin D deficiency is associated with a marked increase in the risk of pneumonia [37], and most human vitamin D is acquired via sun exposure. Thus, extended periods of low UV light could result in an increased susceptibility to $S$. pneumoniae infection resulting from a lack of vitamin $\mathrm{D}$ production, though the week-to-week fluctuations in risk described in this paper may be too rapid to represent a vitamin $\mathrm{D}$ effect.

An alternative mechanism of action of UV radiation in reducing IPD risk could be direct effects of radiation on pathogen survival. Many bacterial respiratory pathogens, including pneumococcus, are transmitted in respiratory secretions over short distances (i.e., via "large droplet transmission"), and thus encounter the physical environment directly during transmission events. The bactericidal effects of UV-B radiation have been well known for decades; such radiation inactivates bacteria by causing harmful genetic mutations through creation of pyrimidine dimers [38]. A model of UV effect via diminished transmissibility, rather than decreased host susceptibility, is supported by our finding that UV effect is strongest in the youngest individuals in the population (i.e., toddlers), where disease risk is likely to be driven by mobility, contact with peers, prolonged carriage and carelessness with respiratory secretions. We found very little protective effect against IPD in oldest individuals, whose risk may be more strongly linked to immune senescence than to high rates of contact with infectious contemporaries $[39,40]$.

An unexpected finding in our case-crossover analysis was the identification of increased levels of ambient sulphur oxides with diminished risk of IPD. This may represent a chance association, due to the established association 


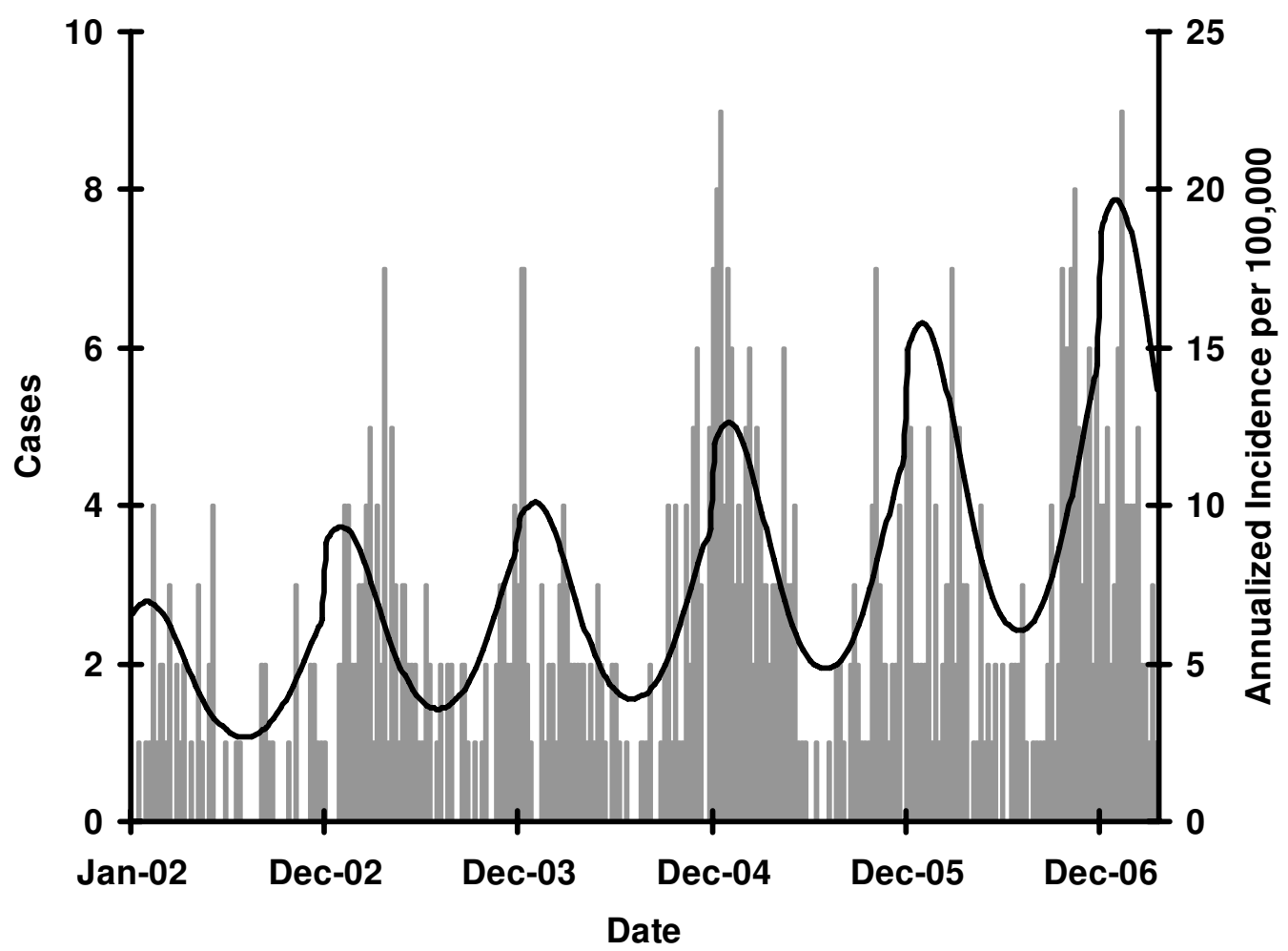

\section{Figure 3}

Trends in Invasive Pneumococcal Disease in Philadelphia County. Bars represent actual case counts, and the curve depicts expected incidence of disease occurrence based on a multivariable Poisson regression model including sine and cosine oscillators, an annual term, and a linear spline term with a knot at January I, 2004. Reported cases are seasonal (wintertime predominant); incidence increases sharply in 2002 and 2003 with the introduction of mandatory reporting, and more slowly thereafter, as described in the text.

between sulphur dioxide and adverse respiratory outcomes [32], as well as the previously described correlation between ambient sulphur dioxide and pneumonia risk [3]. Nonetheless, this association may warrant further exploration; for example, ambient air pollutants might have adverse effects on respiratory tract pathogens as well as hosts.

Other findings in this study are also worthy of comment; in Philadelphia, the wintertime peak in pneumococcal incidence occurred about six weeks later than previously been described in U.S. adults [5]. In addition, a gradual increase in cases was observed during the 5-year study period. We suspect that this increase is less likely to represent a true surge in disease rates, which have actually been falling in the U.S. with the introduction of 7-valent conjugate pneumococcal vaccine [41]; rather, we suspect that this increase, which is more attenuated after 2003, represents the gradual increase in reporting that commonly fol- lows implementation of new infectious disease reporting requirements [42].

Like any observational study, ours has several limitations. First among these is our heavy reliance on public health surveillance data which is known to suffer from underreporting of notifiable infectious diseases [43]. Thus our data set may be incomplete, consisting of only a subset of the cases of IPD in Philadelphia during the study period. However, selection bias will only be introduced if the notification of infectious diseases to public health was correlated with meteorological patterns (e.g., cases which occur during days with higher UV index have a greater likelihood of being diagnosed and reported), which seems unlikely [44]. Second, we obtained weather data from a single site at Philadelphia International Airport, and air pollution and UV data were averaged over several locations throughout the county, which may not represent the true exposure status of individual cases. This is 
Table 2: Weekly Weather Patterns and Incidence of Invasive Pneumococcal Disease in Philadelphia.

\begin{tabular}{|c|c|c|c|c|c|c|}
\hline \multirow[b]{2}{*}{ Environmental or Meteorological Exposure } & \multicolumn{3}{|c|}{ Univariable Models } & \multicolumn{3}{|c|}{ Multivariable Modela, b } \\
\hline & IRR & $(95 \% \mathrm{Cl})$ & $P$ & IRR & $(95 \% \mathrm{Cl})$ & $P$ \\
\hline Cooling Degree-Days $\left({ }^{\circ} \mathrm{C}\right)^{\mathrm{b}}$ & 0.92 & $(0.90-0.94)$ & $<0.001$ & 0.97 & $(0.94$ to 1.00$)$ & 0.054 \\
\hline Maximum Temperature $\left({ }^{\circ} \mathrm{C}\right)$ & 0.97 & $(0.96-0.97)$ & $<0.001$ & 1.03 & (1.003 to 1.06$)$ & 0.028 \\
\hline Minimum Temperature $\left({ }^{\circ} \mathrm{C}\right)$ & 0.96 & $(0.95-0.97)$ & $<0.001$ & $\ldots$ & $\ldots$ & $\ldots$ \\
\hline Relative Humidity (\%) & 0.98 & $(0.97-0.99)$ & 0.002 & $\ldots$ & $\ldots$ & $\ldots$ \\
\hline UV Index & 0.89 & $(0.87-0.92)$ & $<0.001$ & 0.70 & $(0.54-0.91)$ & 0.007 \\
\hline Sulphur Oxides $(\mathrm{ppm} \times 100)$ & 1.73 & $(1.27-2.37)$ & 0.002 & $\ldots$ & $\ldots$ & $\ldots$ \\
\hline Average Wind Speed $(\mathrm{km} / \mathrm{h})$ & 1.01 & $(1.006-1.015)$ & $<0.001$ & $\ldots$ & $\ldots$ & $\ldots$ \\
\hline
\end{tabular}

NOTE: Incidence rate ratios (IRRs) reflect change in disease risk per unit change in the meteorological variable in question. $\mathrm{Cl}$, confidence interval; ppm, parts per million.

aThe model was also adjusted for seasonal oscillation, cumulative cases during the prior month, calendar year and year-squared.

bModel deviance statistic chi-squared $=3156$ on 9317 d.f., $P=1.000$.

'Cooling degree days are defined as the number of degrees a daily mean temperature is above $24^{\circ} \mathrm{C}$. For example, a day with an average temperature of $27^{\circ} \mathrm{C}$ would have 3 cooling degree-days.

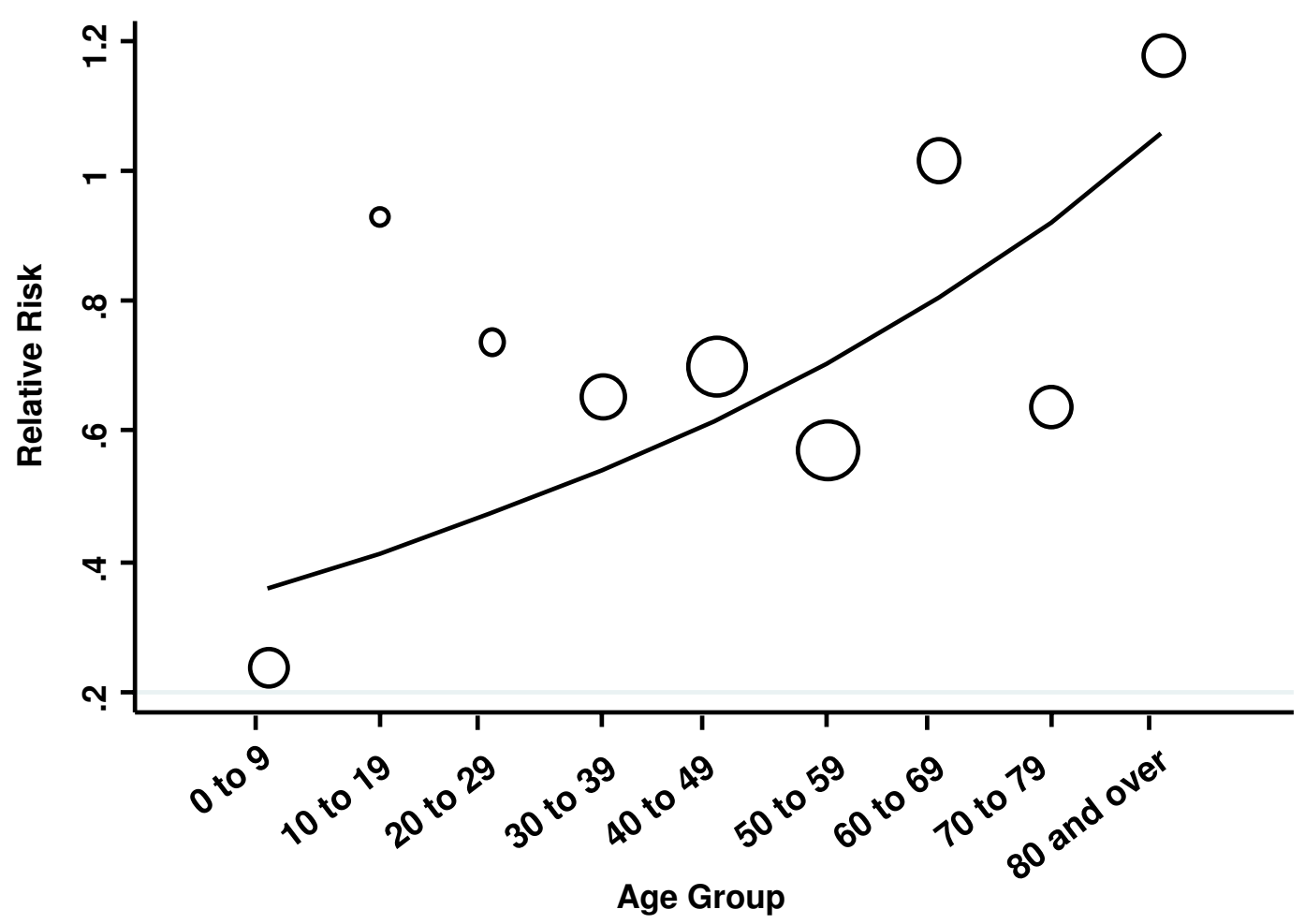

\section{Figure 4}

Changing Effect of UV Radiation on Invasive Pneumococcal Disease Risk by Age Group. Figure constructed by performing meta-regression using age-stratum specific estimates of the effect of a single unit increase clear-sky UV index on the incidence of invasive pneumococcal disease. A log-linear increase in the effect of UV index is observed with decreasing age. 
Table 3: Associations Between Acute Environmental Exposures and Invasive Pneumococcal Disease by Case-Crossover Analysis.

\begin{tabular}{|c|c|c|c|c|c|c|}
\hline \multirow[b]{2}{*}{ Exposure } & \multicolumn{3}{|c|}{$\begin{array}{c}\text { Incubation Period } \\
\text { (I-3 Days Prior to Case Occurrence) }\end{array}$} & \multicolumn{3}{|c|}{$\begin{array}{c}\text { Prior to Incubation Period } \\
\text { (4-6 Days Prior to Case Occurrence) }\end{array}$} \\
\hline & OR & $(95 \% \mathrm{Cl})$ & $P$ & OR & $(95 \% \mathrm{Cl})$ & $P$ \\
\hline \multicolumn{7}{|l|}{ Meteorological } \\
\hline $\begin{array}{l}\text { Cooling Degree- } \\
\text { Days }\left({ }^{\circ} \mathrm{C}\right)\end{array}$ & 0.878 & $0.624-1.236$ & 0.456 & 0.926 & $0.676-1.270$ & 0.635 \\
\hline $\begin{array}{l}\text { Maximum } \\
\text { Temperature } \\
\left({ }^{\circ} \mathrm{C}\right)\end{array}$ & 1.036 & $0.855-1.256$ & 0.717 & 0.997 & $0.822-1.209$ & 0.974 \\
\hline $\begin{array}{l}\text { Minimum } \\
\text { Temperature } \\
\left({ }^{\circ} \mathrm{C}\right)\end{array}$ & 0.994 & $0.820-1.204$ & 0.948 & 1.039 & $0.858-1.258$ & 0.694 \\
\hline $\begin{array}{l}\text { Atmospheric } \\
\text { Pressure }(\mathrm{kPa})\end{array}$ & 1.026 & $0.848-1.24 \mid$ & 0.794 & 1.013 & $0.834-1.230$ & 0.895 \\
\hline $\begin{array}{l}\text { Precipitation } \\
(\mathrm{mm})\end{array}$ & 0.954 & $0.783-1.162$ & 0.6400 & 0.897 & $0.731-1.101$ & 0.300 \\
\hline $\begin{array}{l}\text { Relative } \\
\text { Humidity (\%) }\end{array}$ & 1.038 & $0.844-1.275$ & 0.725 & 0.989 & $0.804-1.217$ & 0.916 \\
\hline UV Index & 1.148 & $0.944-1.396$ & 0.168 & $1.06 \mathrm{I}$ & $0.874-1.289$ & 0.548 \\
\hline $\begin{array}{l}\text { Average Wind } \\
\text { Speed }(\mathrm{km} / \mathrm{h})\end{array}$ & 0.900 & $0.737-1.098$ & 0.298 & 1.045 & $0.85 \mathrm{I}-1.283$ & 0.6739 \\
\hline \multicolumn{7}{|l|}{ Air Quality } \\
\hline $\begin{array}{l}\text { Sulphur Oxides } \\
\text { (ppm) }\end{array}$ & 0.747 & $0.603-0.925$ & 0.007 & 1.425 & $0.952-1.425$ & 0.138 \\
\hline $\begin{array}{l}\text { Oxides of } \\
\text { Nitrogen (ppm) }\end{array}$ & 0.918 & $0.735-1.147$ & 0.452 & 1.144 & $0.930-1.406$ & 0.203 \\
\hline $\begin{array}{l}\text { Carbon } \\
\text { Monoxide (ppm) }\end{array}$ & 0.925 & $0.751-1.139$ & 0.461 & 0.996 & $0.809-1.227$ & 0.971 \\
\hline PMIO $\left(\mu \mathrm{g} / \mathrm{m}^{3}\right)$ & 0.215 & $0.732-3.999$ & 0.215 & 1.199 & $0.523-2.750$ & 0.668 \\
\hline Ozone (ppm) & 1.018 & $0.830-1.249$ & 0.861 & 0.904 & $0.730-1.118$ & 0.351 \\
\hline
\end{tabular}

NOTE: OR, odds ratio; ppm, parts per million; kPa, kilopascals; PMI0, particulates 10 micrometers or less in diameter. Presented odds ratios are those associated with upper tertile of exposures during incubation period. No significant associations were detected in analyses using raw exposure data.

probable non-differential misclassification, and will bias the results towards the null hypothesis. The effects seen here are most likely conservative, weakening the strength of observed associations and suggesting our estimates tend towards the lower bound [44].

\section{Conclusion}

In summary, we described the occurrence of IPD in a major U.S. urban center and found that incidence was associated with marked wintertime seasonality that may be partly explained by diminished exposure to UV-B radiation in winter months. Further study is needed, but this result is consistent with observed patterns of respiratory infectious disease, and would be consistent with several biologically plausible models of effect. As the nature of future changes in UV radiation related to climate change are more difficult to predict than general changes in temperatures or precipitation patterns, the implications of these findings for future pneumococcal disease epidemiology are unclear [45]. Nonetheless, we believe this obser- vation goes some way towards explaining the notable seasonality of IPD, and could conceivably lead to novel disease control strategies through improved understanding of this common and virulent infectious disease.

\section{Competing interests}

The authors declare that they have no competing interests.

\section{Authors' contributions}

AW performed the majority of the analysis and interpretation of the data, and drafted the manuscript. CJ and CS acquired the case and exposure data, and each performed revisions of the manuscript. LK analysed and interpreted data, and was involved in drafting and revising the manuscript. VN adapted the analysis tools for the data, assisted in its interpretation and was involved in critically reviewing the manuscript. DF performed data analysis, interpretation, and was involved in both the drafting and critical review process of the manuscript. All authors have given approval for the final version to be published. 


\section{Additional material}

\section{Additional file 1}

Graph shows trends in invasive pneumococcal disease incidence by age group in Philadelphia from 2002 to 2007. No differences in trends are observed across age groups.

Click here for file

[http://www.biomedcentral.com/content/supplementary/14712334-9-196-S1.PPT]

\section{Additional file 2}

Graph shows trends in invasive pneumococcal disease case fatality rate (\%) by age group in Philadelphia from 2002 to 2007. No differences in trends are observed across age groups.

Click here for file

[http://www.biomedcentral.com/content/supplementary/14712334-9-196-S2.PPT]

\section{References}

I. Dowell SF, Ho MS: Seasonality of infectious diseases and severe acute respiratory syndrome-what we don't know can hurt us. The Lancet Infectious Diseases 2004, 4:704-8.

2. Singer C: A Short History of Medicine. In Ancient Greece Ist edition. New York: Oxford University Press; 1928: I-26.

3. Kim PE, Musher DM, Glezen WP, Rodriguez-Barradas MC, Nahm WK, Wright CE: Association of invasive pneumococcal disease with season, atmospheric conditions, air pollution, and the isolation of respiratory viruses. Clin Infect Dis 1996, 22:100-6.

4. Talbot TR, Poehling KA, Hartert TV, Arbogast PG, Halasa NB, Edwards KM, Schaffner W, Craig AS, Griffin MR: Seasonality of invasive pneumococcal disease: temporal relation to documented influenza and respiratory syncytial viral circulation. American Journal of Medicine 2005, I I 8:285-9I.

5. Dowell SF, Whitney CG, Wright C, Rose CE Jr, Schuchat A: Seasonal patterns of invasive pneumococcal disease. Emerging Infectious Diseases 2003, 9:573-9.

6. Fisman DN, Lim S, Wellenius GA, Johnson C, Britz P, Gaskins M, Maher J, Mittleman MA, Spain CV, Haas CN, et al.: It's not the heat, it's the humidity: wet weather increases legionellosis risk in the greater Philadelphia metropolitan area. Journal of Infectious Diseases 2005, 192:2066-73.

7. Jensen ES, Lundbye-Christensen S, Pedersen L, Sorensen HT, Schonheyder HC: Seasonal variation in meningococcal disease in Denmark: relation to age and meningococcal phenotype. Scandinavian Journal of Infectious Diseases 2003, 35:226-9.

8. Austrian R: The pneumococcus at the millennium: not down, not out. Journal of Infectious Diseases 1999, I 79(Suppl 2):S338-4I.

9. Robinson KA, Baughman W, Rothrock G, Barrett NL, Pass M, Lexau C, Damaske B, Stefonek K, Barnes B, Patterson J, et al.: Epidemiology of invasive Streptococcus pneumoniae infections in the United States, 1995-1998: Opportunities for prevention in the conjugate vaccine era. JAMA 200I, 285: I729-35.

10. Ortqvist A, Hedlund J, Kalin M: Streptococcus pneumoniae: epidemiology, risk factors, and clinical features. Seminars in Respiratory \& Critical Care Medicine 2005, 26:563-74.

II. Daneman N, McGeer A, Green K, Low DE: Macrolide resistance in bacteremic pneumococcal disease: implications for patient management. Clin Infect Dis 2006, 43:432-8.

12. Whitney CG, Farley MM, Hadler J, Harrison LH, Bennett NM, Lynfield R, Reingold A, Cieslak PR, Pilishvili T, Jackson D, et al.: Decline in invasive pneumococcal disease after the introduction of protein-polysaccharide conjugate vaccine. N Engl J Med 2003, 348: $1737-46$.

13. Emergence of antimicrobial-resistant serotype I9A Streptococcus pneumoniae--Massachusetts, 200 I-2006. MMWR Morb Mortal Wkly Rep 2007, 56: 1077-80.

14. Pichichero ME, Casey JR: Emergence of a multiresistant serotype I9A pneumococcal strain not included in the 7-valent conjugate vaccine as an otopathogen in children. Jama 2007, 298: $1772-8$

15. Fisman DN: Seasonality of infectious diseases. Annu Rev Public Health 2007, 28: I 27-43.

16. Intergovernmental Panel on Climate Change: Climate Change 2007: Impacts, Adaptation and Vulnerability. Contribution of Working Group II to the Fourth Assessment Report of the Intergovernmental Panel on Climate Change. Cambridge, UK: Cambridge University Press; 2007.

17. Population Division, US Census Bureau: Population estimates. 2007 [http://www.census.gov/popest/estimates.php]. City: U.S. Department of Commerce Last accessed January 29, 2008.

18. Case definitions for infectious conditions under public health surveillance. Centers for Disease Control and Prevention. MMWR Recomm Rep 1997, 46: I-55.

19. National Climate Data Center, NOAA Satellite and Information Service: Online climate data directory. 2007 [http://
City: Iwf.ncdc.noaa.gov/oa/climate/climatedata.html\#surface]. City: National Oceanic and Atmospheric Administration, U.S. Department of Commerce Last accessed January 29, 2008.

20. U.S. Environmental Protection Agency: Air Quality System. 2007 [http://www.epa.gov/ttn/airs/airsaqs/aqsweb/]. City: U.S. Environmental Protection Agency Last accessed January 29, 2008.

21. Climate Prediction Center, NW Service: UV Index Bulletins Archive. 2007 [http://www.cpc.ncep.noaa.gov/products/strato sphere/uv index/uv archive.shtml]. City: National Oceanic and Atmospheric Administration, U.S. Department of Commerce Last accessed January 29, 2008.

22. Diggle P: Time Series: A Biostatistical Introduction. Oxford, UK: Oxford University Press; 1990.

23. Woodward $M$ : Modelling quantitative outcome variables. In Epidemiology: Study Design and Data Analysis 2nd edition. Boca Raton, FL: Chapman \& Hall/CRC; 2005.

24. Hosman D, Lemeshow S: Applied Logistic Regression. Ist edition. New York: John Wiley and Sons; I989:82-I34.

25. Deeks J, Altman D: Effect measures for meta-analysis of trials with binary outcomes. In Systematic Reviews in Health Care: MetaAnalysis in Context Edited by: Egger M, Davey Smith G, Altman D. London, UK: BMJ Publishing Group; 1995:313-335.

26. Levy D, Lumley T, Sheppard L, Kaufman J, Checkoway H: Referent selection in case-crossover analyses of acute health effects of air pollution. Epidemiology 200I, I 2: I86-92.

27. Lumley T, Levy D: Bias in the case crossover design: implications for studies of air pollution. Environmetrics 2000:689-704.

28. Control of Communicable Diseases Manual. 17th edition. Washington, DC: American Public Health Association; 2000.

29. Dowell SF: Seasonal variation in host susceptibility and cycles of certain infectious diseases. Emerging Infectious Diseases 200I, 7:369-74.

30. Dushoff J, Plotkin JB, Levin SA, Earn DJ: Dynamical resonance can account for seasonality of influenza epidemics. Proc Natl Acad Sci USA 2004, I 0 I: 16915-6.

3I. Schwartz J: PMI0, ozone, and hospital admissions for the elderly in Minneapolis-St. Paul, Minnesota. Arch Environ Health 1994, 49:366-74.

32. Health effects of outdoor air pollution. Committee of the Environmental and Occupational Health Assembly of the American Thoracic Society. Am J Respir Crit Care Med 1996, I 53:3-50.

33. Cannell JJ, Vieth R, Umhau JC, Holick MF, Grant WB, Madronich S, Garland CF, Giovannucci E: Epidemic influenza and vitamin D. Epidemiology \& Infection 2006, | 34: | | 29-40.

34. Dowell SF: Seasonal variation in host susceptibility and cycles of certain infectious diseases. Emerg Infect Dis 2001, 7:369-74.

35. van Etten E, Mathieu C: Immunoregulation by I,25-dihydroxyvitamin D3: basic concepts. Journal of Steroid Biochemistry \& Molecular Biology 2005, 97:93-I0I.

36. Schutte BC, McCray PB Jr: [beta]-defensins in lung host defense. Annual Review of Physiology 2002, 64:709-48.

37. Muhe L, Lulseged S, Mason KE, Simoes EA: Case-control study of the role of nutritional rickets in the risk of developing pneumonia in Ethiopian children. Lancet 1997, 349:1801-4.

38. Brickner PW, Vincent RL, First M, Nardell E, Murray M, Kaufman W: The application of ultraviolet germicidal irradiation to control transmission of airborne disease: bioterrorism countermeasure. Public Health Rep 2003, I I 8:99- I I 4. 
39. Hogberg L, Geli P, Ringberg H, Melander E, Lipsitch M, Ekdahl K: Age- and serogroup-related differences in observed durations of nasopharyngeal carriage of penicillin-resistant pneumococci. J Clin Microbiol 2007, 45:948-52.

40. Smithson SL, Kolibab K, Shriner AK, Srivastava N, Khuder S, Westerink MA: Immune response to pneumococcal polysaccharides 4 and 14 in elderly and young adults: analysis of the variable light chain repertoire. Infect Immun 2005, 73:7477-84.

4I. Lexau CA, Lynfield R, Danila R, Pilishvili T, Facklam R, Farley MM, Harrison LH, Schaffner W, Reingold A, Bennett NM, et al.: Changing epidemiology of invasive pneumococcal disease among older adults in the era of pediatric pneumococcal conjugate vaccine. Jama 2005, 294:2043-5I.

42. Janes GR, Hutwagner LC, Cates W Jr, Stroup DF, Williamson GD: Descriptive Epidemiology: Analyzing and Interpreting Surveillance Data. In Principles and Practice of Public Health Surveillance 2nd edition. Edited by: Steven REC, Teutsch M. New York: Oxford University Press; 2000:116-168.

43. Doyle TJ, Glynn MK, Groseclose SL: Completeness of notifiable infectious disease reporting in the United States: an analytical literature review. American Journal of Epidemiology 2002, 155:866-74.

44. Grimes DA, Schulz KF: Bias and causal associations in observational research. Lancet 2002, 359:248-52.

45. Talaas P, Kaurola J, Kylling A, Shindell D, Sausen R, Dameris M, Grewe $\checkmark$, Herman J, Damski J, Steil B: The impact of greenhouse gases and halogenated species on future solar UV radiation doses. Geophysical Research Letters 2000, 27: I 127-30.

\section{Pre-publication history}

The pre-publication history for this paper can be accessed here:

http://www.biomedcentral.com/1471-2334/9/196/pre pub

Publish with Bio Med Central and every scientist can read your work free of charge

"BioMed Central will be the most significant development for disseminating the results of biomedical research in our lifetime. "

Sir Paul Nurse, Cancer Research UK

Your research papers will be:

- available free of charge to the entire biomedical community

- peer reviewed and published immediately upon acceptance

- cited in PubMed and archived on PubMed Central

- yours - you keep the copyright

Submit your manuscript here:

http://www.biomedcentral.com/info/publishing_adv.asp 